\title{
An Overview of Management of Cancer Approach with Medical and Dental Considerations
}

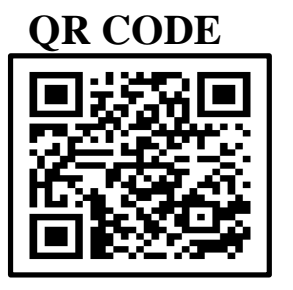

\section{DEBASHIS ROY*1, NAJMUS SAHAR ${ }^{1}$ PRADEEP TANGADE², SURBHI PRIYADARSHI', MUSHAHID HASAN3}

This review emphasizes about making the members of the professional Colleges aware of some important aspects of oral cancer in particular \& cancer of body in general and its impact on the Dental Surgeons to be a part of the weapon against fighting this devastating disease. Cancer is the major public health problem affecting developed and developing countries. Therefore this review focusses on cancer management by taking into mind dental and medical considerations.

KEYWORDS: Cancer, Dentistry, Chemotherapy

\section{INTRODUCTION}

Cancer in all forms are resulting in about $12 \%$ of death throughout the world. ${ }^{1}$ In developed countries cancer is the second leading cause of death accounting for $21 \%(2.5$ million) of all mortality. ${ }^{2}$ In developing countries cancer ranks third as a cause of death and accounts for 9.5\% (3.8 million) of all deaths. ${ }^{3}$

WHO has estimated that $91 \%$ of oral cancers in SouthEast Asia are directly attributable to the use of tobacco and total cancer burden in India for all sites will increase from 7 lakhs new cases per year to 14 lakhs per year by $2026 .{ }^{4}$ Worldwide, cancer of the mouth results in the death of 2 million people every year. In USA, it is the leading killer disease next to the cardio vascular disease. As in a survey by ICMR it has been stated that amongst all Cancer of our body constitutes 30\% of the oral cancer which is a matter of big concern. Cancer does not spare rich or poor. ${ }^{5}$ Underprivileged people are either unaware or are not able to afford the required treatment. Oral Cancer occurs mainly among poor people who have high intake of gutkha, khaini etc. Other Cancers of our body e.g. cancer of ovary, uterus, breast, colon, etc are more common among the rich people; but this section of society can afford the treatment. ${ }^{6}$

\section{DISCUSSION}

Very frequently we the "dental surgeon" have to examine the patients suffering from oral cancers.

Pre-malignant lesions if treated properly, may not turn into malignancy and hence, patients with squamous cell carcinoma constitutes around $90 \%$ of oral cancers and is a malignant one. ${ }^{7}$
Stage I \& Stage II of squamous cell carcinoma are amenable to surgery, whereas Stage III \& IV involves bone, vascular structures and multiple lymph nodes are treated with combination therapy consisting of surgery and irradiation surgery and chemotherapy. ${ }^{8}$

Irradiation is done by three methods: interstitial, implantation as done in brachytherapy and external beam methods. Radiation therapy is usually given within 6 weeks of surgical dissection. ${ }^{9}$ The tumoricidal dose of external beam irradiation ranges from 5000 CGy (Centigray) to 700o CGy given in separate dose of 150-200 CGy over 6 to 8 weeks period. ${ }^{10}$

Higher Survival rates are associated with early diagnosis, younger age, early cancer Stage I \& Stage II involving anterior sites with cancer depth of $5 \mathrm{~mm}$ or less and carcinomas that do not metastasize in bone. Recurrence are more common in patients who do not stop alcohol and tobacco products. ${ }^{11}$

\section{DENTAL MANAGEMENT IN PREVIEW OF RECOGNIZATION OF CANCER AND MEDICAL CONSIDERATIONS}

When a patient visits the dentist, he should have a consistent approach for ascertaining related medical, historical and clinical information from the patient. A dentist should ask the patient the following: "Have you experienced any change in your health since the last visit?", "Are you aware of any lump on bump developing under your arm or in your neck for any apparent reasons", "do your suffer from any abnormal bleeding from any site such as blood in the stool" and "do you suffer 
from any ulcer in your tongue or mucosa which is did not heal within 3 weeks?". ${ }^{2}$ The patient should be examined thoroughly for any hard, fixed or matted lymph nodes. A pre-treatment oral evaluation is mandatory for all cancer patients before initiation of cancer therapy for:

1. Ruling out any oral disease that may aggravate during cancer therapy.

2. Providing a baseline for comparison and monitoring squeal of Irradiation and chemotherapy damage.

3. Minimizing oral discomfort during cancer therapy.

\section{IRRADIATION}

Most of the dental surgeons are aware of the complication of irradiation and chemotherapy. In irradiation therapy the healthcare professionals are mainly are concerned about:

1. Osteoradionecrosis: This complication is greatest in posterior mandibular sites \& subjects who have received radiation dosage in excess of 6500 CGy. This is the new SI unit earlier it was RAD (Radiation Absorbed Dose). Now $100 \mathrm{RAD}=1 \mathrm{CGy} .{ }^{13}$

2. The dental surgeon should be aware of another important factor which is basically development of "carotid stenosis" which is likely to develop in carotid artery if irradiation is given at a dose $45 \mathrm{~Gy}$ or more in neck region. This may add up as a risk factor of stroke.

3. Risk is greater for patients who are dentulous rather than edentulous.

4. To reduce the possibility of developing osteoradionecrosis, the dental surgeon should think of selecting edentulous over extraction and use of local anesthesia without adrenaline.

5. Atraumatic surgical procedure as much as possible should be employed.

6. Prophylactic antibiotics plus antimicrobials should be given during the healing process and dosage should be higher than the normal schedule.

7. Hyperbaric oxygen therapy using sequential daily dives under 2 atmospheric pressure in a chamber should be given.

8. Once necrosis has occurred conservative management is usually indicated and exposed bone should be irrigated with saline and antibiotic solution.

Amongst the other complications are :-

i. Xerostomia

ii. Mucositis

iii. Submandibular lymphadenopathy

iv. Radiation caries

v. Burning mouth syndrome

\section{vi. Dysgeusia or Ageusia}

\section{CHEMOTHERAPY}

If the cancer patient receiving chemotherapy has to undergo any oral procedure, dental surgeon should adjust the patient's dosage based on routine hemogram and clotting factors. ${ }^{14}$ Routine oral procedure can't be done if the granulocyte count particularly Neutrophil count is below $1500 / \mathrm{mm}^{3}$ and platelet count less than $50,000 / \mu \mathrm{m}$. These patients might develop thrombocytopenia and neutropenia due to high dose of chemotherapy resulting in bone marrow depression. If it is a chemotherapeutic induced myelosuppression, it will recover in 6 weeks spontaneously. ${ }^{15}$ One of the most important concern is indwelling Hickman Catheter or port that are susceptible to infection which can be prevented by prophylactic antibiotics given during oral procedures.

For a patient who is undergoing radiotherapy or chemotherapy the following notes should be kept in mind by the dental surgeons prior to any dental procedure. ${ }^{16}$

1. Acute toxicity occurs immediately during and after radiotherapy \& chemotherapy. The severity of such toxicity is directly proportional to cytotoxic drugs. Chemotherapy is most effective at killing cells that are rapidly dividing.

2. Delayed toxicity occurs in several months to years after radiation therapy. Amongst all the toxicities, a dental surgeon encounters patients with mucositis, xerostomia, radiation caries, secondary infection, sensitivity of teeth, complete agesia, muscular dysfunction and osteoradionecrosis. Osteoradionecrosis is a condition characterized by exposed base bone that fails to heal even months after radiation. This condition is most common in posterior mandibular sites where vascularity is very less.

Bisphosphonates: These have two phosphonate groups hence are called diphosphonates. It is a class of drugs that prevent loss of bone density and is used to treat osteoporosis and similar disease. They reduce the risk of fracture in post-menopausal women with osteoporosis. ${ }^{17}$ Bone tissue undergoes constant remodelling by bone creating osteoblasts and bone destroying osteoclasts. Bisphosphonates inhibits the digestion of bone by encouraging osteoclasts to undergo-apoptosis.

\section{CONCLUSION}

Cancer is emerging as important non-communicable public health problem of the world. The epidemiology of cancer, its control and prevention measures are 
applicable to the world including the Indian subcontinent. The major risk factors for the disease are tobacco, dietary habits, inadequate physical activity, alcohol consumption and infections due to viruses. The greatest impact to reduce the burden of cancer comes from primary prevention, extensive persuasive health education being the basic one.

\section{REFERENCES}

1. Fedele S. Diagnostic aids in the screening of oral cancer. Head Neck Oncol. 2009;1:5. https://doi.org/10.1186/1758-3284-1-5.

2. Burket's oral medicine: diagnosis and treatment. 1oth Ed. New York: BC Decker Inc, 2003.

3. Rath GK, Mohanty BK. Textbook of Radiation Oncology: Principles and Practice. 1st edition: Elsevier; 2007.

4. Wood NK, Goaz PW. Differential Diagnosis of Oral and Maxillofacial Lesions. 5th Edition. Elsevier; 1997.

5. Shah JP, Lydiatt W. Treatment of Cancer of the head and neck. CA Cancer J Clin. 1995;45(6):352-68. https://doi.org/10.3322/canjclin.45.6.352.

6. Tabuchi T. Cancer and Socioeconomic Status. In: Kondo K. (eds) Social Determinants of Health in Noncommunicable Diseases. Springer Series on Epidemiology and Public Health. Springer, Singapore; 2020.

7. Tabuchi T. Cancer and Socioeconomic Status. In: Kondo K. (eds) Social Determinants of Health in Noncommunicable Diseases. Springer Series on Epidemiology and Public Health. Springer, Singapore; 2020.

8. Mittal BR, Parihar AS. Basic Physics and Radiation Safety in Nuclear Medicine. Indian J Nucl Med. 2019;34(2):18o-1. https://doi.org/10.4103/ijnm.IJNM_47_19
9. Haring J, Howarten L. Dental radiography. Principles and techniques. 3rd ed. Philadelphia: Elsevier; 2006. 10. Olive PL, Durand RE. Fluorescent nitroheterocytes of identifying hypoxic cells. Cancer Research 1983;43:327680.

11. Chapman JD. The detection and measurement of hypoxic cells in solid tumors. Cancer. 1984 Dec 1;54(11):2441-9. https://doi.org/10.1002/10970142(19841201) 54:11<2441::aid-cncr2820541122>3.0.co;2-s.

12. Chapman JD, Urtasun RC. The application in radiation therapy of substances which modify cellular radiation response. Cancer. 1977;40(1 Suppl):484-8. https://doi.org/10.1002/1097-0142(197707)40:1+<484::aidcncr2820400713>3.0.co;2-u.

13. Cox JD. Large dose fractionation (hypofractionation). Cancer 1985;55:2105-111. https://doi.org/10.1002/10970142(19850501) 55:9+<2105::

AID-

CNCR2820551412>3.0.CO;2-T

14. Zaider M, Wuu CS. The effect of sublethal damage recovery and cell cycle progression on the survival probability of cells exposed to radioactive sources. $\mathrm{Br}$ J Radiol. 1995;68(805):58-63. https://doi.org/10.1259/ooo71285-68-805-58.

15. Wang CC, Blitzer PH, Suit HD. Twice-a-day radiation therapy for cancer of the head and neck. Cancer. 1985 May 1;55(9 Suppl):2100-4. https://doi.org/10.1002/1097o142(19850501) 55:9+<2100::aid-cncr2820551411>3.o.co;2-a. 16. Barkley HT Jr. Accelerated treatment. Cancer. 1985 May;55(9 Suppl):2112-2117.

17. Evans MDC. Surface applicators for HDR brachytherapy in AIDS-related Kaposi's sarcoma. Int. J. Radiation Oncology Biol. Phys 1977;(30):769-74. https://doi.org/10.1016/so36o-3016(97)oo36o-x. 